\title{
RECRUTAMENTO LARVAL E CRESCIMENTO DE TEREDINIDAE (MOLLUSCA-BIVALVIA) EM REGIÃO ENTREMARÉS DE MANGUEZAIS
}

\author{
Sônia Godoy Bueno Carvalho Lopes \& Walter Narchi \\ Instituto de Biociências da Universidade de São Paulo \\ Departamento de Zoologia \\ (Caixa Postal 11461, 05422-970 São Paulo, SP, Brasil)
}

- Abstract: The larval settlement and growth of Teredinidae in the intertidal region of the Praia Dura mangrove, Ubatuba, SP, were undertaken during one year $(08 / 84$ to $08 / 85)$ using colectors made from mangrove wood. The presence of the first Teredinidae was detected approximately seven month after the inicial experiment and the number of specimens per coletor was small during the sampling period. These results contrast with those obtained by other authors working in a marine environment, but are similar to those obtained in experiments developed in Brazilian estuaries. The differences between data obtained in marine and estuarine environments, might be explained by the lower and more variable salinity gradient in estuaries. Larval settlement data revealed that the most abundant species was Nausitora fusticula (Jeffreys, 1860), which settles on wood prefrerably in March, and has an initial growth rate of $1.86 \mathrm{~mm} /$ day. The other Teredinidae species Bankia fimbriatula Moll \& Roch, 1931, Bankia rochi Moll, 1931 and Neoteredo reynei (Bartsch, 1920), occurred in a very small number of specimens and therefore, their time of settlement and growth rates could not be determined.

- Resumo: O recrutamento larval e o crescimento de Teredinidae na região entremarés do manguezal da Praia Dura, Ubatuba, SP, foi acompanhado durante doze meses (08/84 a 08/85) utilizando coletores construídos com madeira de mangue. $O$ tempo decorrido para se detectar a presença dos primeiros Teredinidae foi de aproximadamente sete meses após o início do experimento e o número de indivíduos por coletor foi muito reduzido no período de amostragem. Esses resultados contrastam com os obtidos por outros autores que instalaram coletores em ambiente marinho, mas são semelhantes aos obtidos por autores que instalaram coletores em regiōes estuarinas do litoral brasileiro. Essas diferenças nos resultados talvez possam ser explicadas pelo fato da salinidade ser mais baixa e mais variável nos estuários que no ambiente marinho. A análise dos dados sobre o recrutamento larval, permite concluir que a espécie mais abundante foi Nausitora fusticula (Jeffreys, 1860), com principal época de instalação em março e taxa inicial de crescimento de 1,86 $\mathrm{mm} /$ dia. As outras espécies de Teredinidae, Bankia fimbriatula Moll \& Roch, 1931, Bankia rochi Moll, 1931 e Neoteredo reynei (Bartsch, 1920), apresentaram pequeno número de indivíduos e em função disso, não foi possível determinar suas épocas de instalação e respectivas taxas de crescimento.

- Descriptors: Teredinidae, Larval settlement, Mangrove, Growth rate, Intertidal environment.

- Descritores: Teredinidae, Recrutamento larval, Manguezal, Taxa de crescimento, Ambiente entremarés. 


\section{Introdução}

Os Teredinidae são bivalves marinhos e de águas salobras que, após um período de vida planctônica, instalam-se na superfície da madeira, sofrem metamorfose e perfuram o substrato, aproveitando parte da madeira raspada por suas conchas, como fonte suplementar de alimentação (Turner, 1966).

Os Teredinidae têm papel significativo na decomposição de troncos e ramos de árvores em manguezal, degradando cerca de $50 \%$ da massa original da madeira em dois anos, o que indica reciclagem da matéria orgânica mais rápida nesse ambiente que a verificada em florestas terrestres, onde não existem teredos (Robertson, 1991).

Trabalhos de levantamento de espécies de teredinídeos brasileiros feitos a partir da análise de animais removidos da própria madeira dos arbustos típicos do ambiente de manguezal, foram feitos por Müller \& Lana (1986, 1987), Reis (1990), Lopes (1991) e Lopes \& Narchi (1993). Os demais foram feitos com coletores de madeira, principalmente de pinho, submersos em água do mar ou em estuário, destacando-se os de Milano \& Lopez (1977/1978), Silva (1985), Tiago (1989), Junqueira et al. (1989, 1991) e Junqueira \& Silva (1991).

O presente trabalho tem por objetivos verificar o recrutamento larval e o crescimento de teredos em ambiente entremarés de manguezais, utilizando coletores construídos com a própria madeira de mangue.

\section{Material e métodos}

O estudo do recrutamento larval e do crescimento de Teredinidae foi realizado no manguezal que se desenvolve às margens do Rio Comprido, na Praia Dura, Ubatuba, SP $\left(45^{\circ} 15^{\circ} \mathrm{W}\right.$ e $23^{\circ} 30^{\prime}$ 'S) (Fig. 1). A experimentação foi iniciada em agosto de 1984 e finalizada em agosto de 1985.

Para realizar esse estudo, foram construídos dois tipos de coletores: os laminados e os maciços. Os laminados foram feitos a partir de ramos de Laguncularia racemosa, espécie de mangue mais abundante no local. Os maciços foram feitos a partir de ramos de $L$. racemosa, Rhizophora mangle e Avicennia schaueriana.

Para o preparo desses coletores, os ramos foram previamente expostos ao sol. A madeira, depois de seca, foi levada à serraria do Instituto de Pesquisas
Tecnológicas em São Paulo, onde ramos foram cortados em segmentos de $25 \mathrm{~cm}$ para fazer coletores maciços. Outros foram cortados longitudinalmente em lâminas de cerca de $0,3 \mathrm{~cm}$ de espessura. As lâminas foram reunidas com o uso de abraçadeiras do tipo "Insulak" e cortados segmentos de $25 \mathrm{~cm}$ de comprimento. $O$ diâmetro desses coletores foi padronizado em torno de $2,4 \mathrm{~cm}$.

Esses coletores foram presos a cordas de náilon e amarrados a árvores no interior do manguezal, bem próximo do substrato (Fig. 2).

Os coletores laminados serviram para a realização de duas séries de experimentos, com base em procedimentos adaptados de Nair (1962): a de longa e a de curta duração. Na primeira, instalaramse 70 coletores ao mesmo tempo para serem retirados 10 a cada mês; na segunda, instalaram-se 10 coletores, para serem retirados após 1 mês, repetindo-se esse procedimento por 12 meses (coletores mensais).

Com os coletores maciços montou-se apenas a série de longa duração, instalando-se ao mesmo tempo 25 coletores de cada espécie de árvore de mangue, para se retirar cinco de cada um deles por mês.

Essas programações foram seguidas até o terceiro mês. Como não ocorreu instalação de Teredinidae nesse período, aumentou-se o intervalo de tempo entre as coletas e variou-se o número de coletores analisados, de acordo com o que consta na Tabela 1.

Paralelamente à essas séries de coletores feitos com madeira de mangue, instalou-se no mesmo local outra série composta por dez coletores laminados construídos com pinho, madeira comumente utilizada nesse tipo de experimento e cedidos pelo Setor de Preservação de Madeiras do Instituto de Pesquisas Tecnológicas (IPT) de São Paulo. As dimensões desses coletores eram semelhantes às dos coletores construídos com madeira de mangue. Esses coletores foram instalados em agosto de $1984 \mathrm{e}$ retirados em março de 1985 , com o objetivo de verificar se o tipo de madeira poderia interferir nos resultados.

Os animais retirados completos dos coletores eram anestesiados com propileno fenoxetol, medidos e fixados por 24 horas em formol $4 \%$, neutralizado. Depois eram transferidos para álcool glicerinado (5 partes de álcool a $85 \%$ para 1 parte de glicerina líquida comercial). 


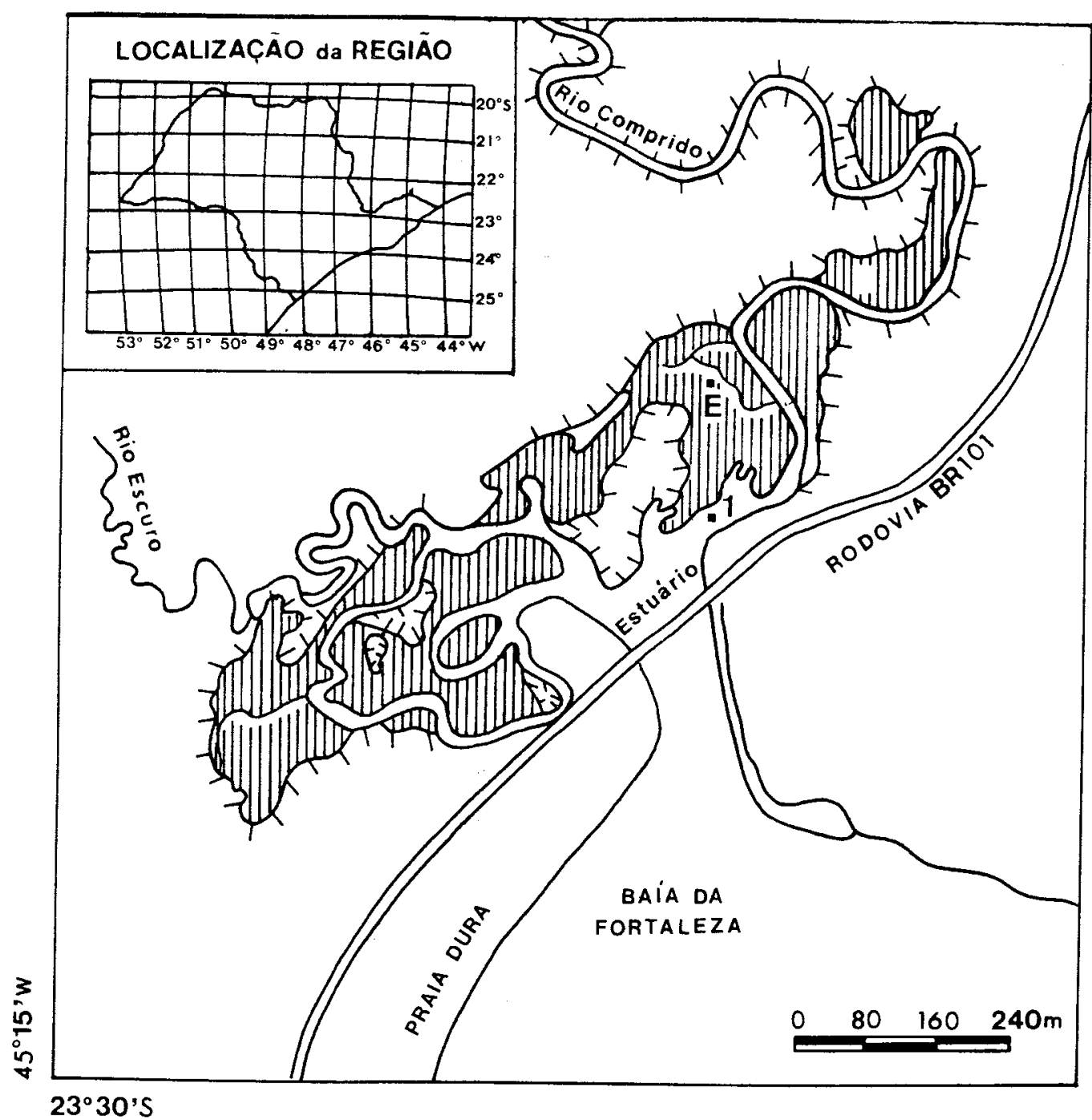

Fig. 1. Mapa da região, indicando o local aproximado onde foram instalados os experimentos (E) e o ponto 1 onde foram feitas as medidas de salinidade da água do Rio Comprido na maré alta; पy limite entre área de manguezal e vegetação de transição.

IIII área de manguezal;

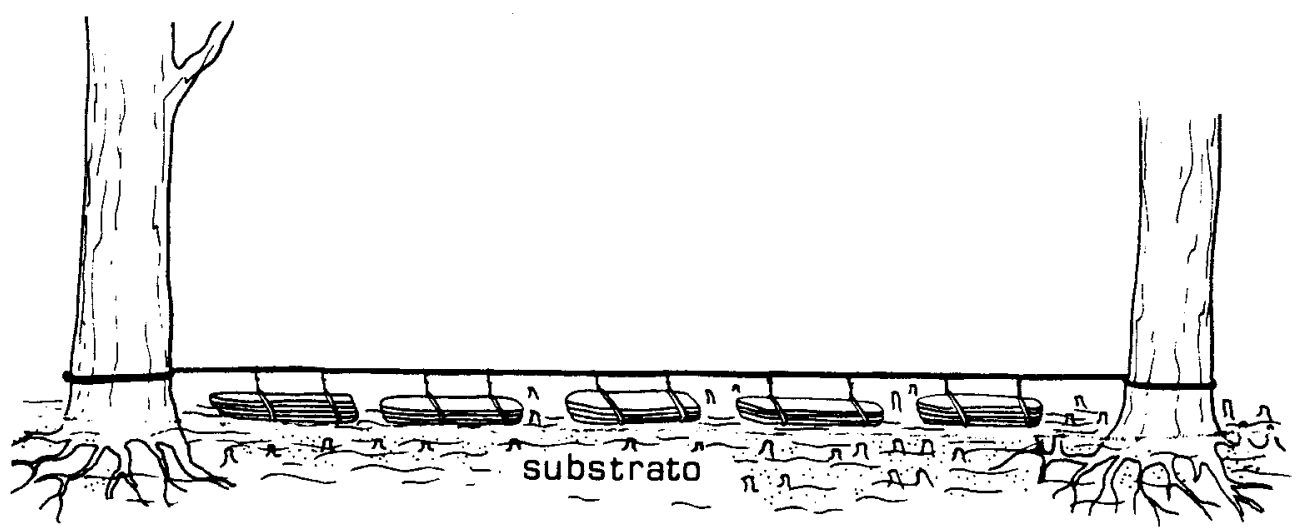

Fig. 2. Esquema da montagem do experimento no interior do bosque de mangue. 
Tabela 1. Número de coletores analisados durante o período de duração da experimentação: 08/84 a 08/85.

$\mathrm{NR}=$ Número de coletores retirados.

$\mathrm{NA}=$ Número de coletores atacados por Teredinidae.

\section{TIPOS DE COLETORES}

\begin{tabular}{|c|c|c|c|c|c|c|c|c|c|c|}
\hline \multicolumn{8}{|c|}{ Longa duração } & & \multirow{2}{*}{\multicolumn{2}{|c|}{$\begin{array}{l}\text { Curta duração } \\
\text { Laminados }\end{array}$}} \\
\hline & \multicolumn{2}{|c|}{ Laminados } & \multicolumn{2}{|c|}{ Maciços } & & & & & & \\
\hline & & & \multicolumn{2}{|c|}{ L.racemosa } & \multicolumn{2}{|c|}{ A.schaueriana } & R.mangle & & & \\
\hline $\begin{array}{l}\text { Data da } \\
\text { retirada }\end{array}$ & NR & NA & $\mathrm{NR}$ & $\mathrm{NA}$ & NR & NA & NR & NA & $\mathrm{NR}$ & NA \\
\hline $09 / 84$ & 10 & 0 & 5 & 0 & 5 & 0 & 5 & 0 & 10 & 0 \\
\hline $10 / 84$ & 10 & 0 & 5 & 0 & 5 & 0 & 5 & 0 & 10 & 0 \\
\hline $12 / 84$ & 15 & 0 & 5 & 0 & 5 & 0 & 5 & 0 & 10 & 0 \\
\hline $03 / 85$ & 20 & 11 & 5 & 0 & 5 & 0 & 5 & 0 & 10 & 0 \\
\hline $04 / 85$ & 10 & 3 & 1 & 0 & 1 & 0 & 1 & 0 & 5 & 0 \\
\hline $08 / 85$ & 5 & 5 & 4 & 1 & 4 & 2 & 4 & 2 & 5 & 0 \\
\hline TOTAL & 70 & 19 & 25 & 1 & 25 & 2 & 25 & 2 & 50 & 0 \\
\hline
\end{tabular}

O número de indivíduos de cada espécie de teredo por coletor, foi calculado considerando os indivíduos retirados completos e as porções do corpo que continham as paletas, estruturas indispensáveis para a diagnose específica.

Estimou-se a dominância mensal de cada espécie de Teredinidae, de acordo com a seguinte fórmula (Silva, 1985):

$\mathrm{Da}=$

$$
\frac{\mathrm{Na}}{\mathrm{Na}+\mathrm{Nb}+\mathrm{Nc} \ldots . .} \quad \times 100
$$

onde $: \mathrm{Da}=$ Dominância da espécie $\mathrm{a}$;

$\mathrm{Na}+\mathrm{Nb}+\mathrm{Nc} . . .=$ Número de indivíduos das espécies a,b,c...

Apenas para a espécie mais abundante foram construidos gráficos de frequêencia por classes de comprimento e da curva de crescimento.

$\mathrm{O}$ número de indivíduos por coleta, considerados para a construção da curva de crescimento, correspondeu a $25 \%$ dos animais coletados completos. Com base nesse número, foram selecionados os maiores indivíduos e calculada a média do comprimento do corpo dos animais para aquela amostra, conforme metodologia adotada por Silva (op. cit.). As taxas de crescimento foram estimadas através do cálculo da diferença entre essas médias, sendo o dado fornecido em $\mathrm{mm} / \mathrm{dia}$.

Em cada coleta mediu-se a salinidade da água de poças localizadas na proximidade do local onde se instalou o experimento (E). A salinidade da água superficial do Rio Comprido na preamar, foi medida semanalmente de setembro a dezembro de 1984 , no ponto 1 (Fig. 1). A determinação dos valores de salinidade foi feita utilizando-se um refratômetro "Goldberg T/C", modelo 10.419, da "American Optical".

\section{Resultados}

A instalação de Teredinidae nos coletores laminados da série de longa duração ocorreu após 7 meses de permanência no local, e nos coletores maciços, apenas após 12 meses. Dos 70 coletores laminados da série de longa duração ocorreu infestação em apenas 19 e dos 75 coletores maciços só houve infestação em 5 , sendo 1 de $L$. racemosa, 2 de $A$. shaueriana e 2 de $R$. mangle (Tab. 1). 
Nos coletores da série de curta duração, que permaneceram no local por um intervalo de tempo que variou de 1 a 4 meses, não houve infestação (Tab. 1).

As espécie de Teredinidae encontradas nos coletores laminados foram, em ordem decrescente de abundância, Nausitora fusticula (Jeffreys, 1860) com 143 indivíduos, Bankia fimbriatula Moll \& Roch, 1931 com 13 indivíduos, Neoteredo reynei (Bartsch, 1920) com 10 indivíduos e Bankia rochi Moll, 1931 com 2 individuos. Não foram identificados 27 individuos por serem muito jovens ou por terem perdido a paleta (Tab. 2). O número total de indivíduos foi de 195 , sendo que, considerando o período de 12 meses, o número médio de indivíduos por coletor foi de 3,25 .

Nos coletores maciços as espécies encontradas foram Nausitora fusticula com 8 indivíduos e
Neoteredo reynei com apenas 1 individuo. Não houve aparecimento de espécies do gênero Bankia .

Nausitora fusticula ocorreu em todos os meses em que houve infestação e sempre foi a espécie dominante. B. fimbriatula ocorreu em março e em agosto enquanto que $B$. rochi ocorreu em março e abril. Neoteredo reynei ocorreu apenas em agosto (Tab. 2).

Nos coletores de pinho que permaneceram no local por sete meses, registrou-se a ocorrência de apenas um individuo, de pequeno tamanho e que em função disso não foi identificado. Esse dado não foi computado para os cálculos de dominância de espécies, pois os coletores de pinho foram utilizados apenas para ver se o tipo de madeira poderia interferir nos resultados.

Tabela 2. Número de indivíduos das espécies de Teredinidae em coletor laminado da série da longa duração.

\begin{tabular}{|c|c|c|c|c|c|}
\hline \multirow[b]{2}{*}{ Espécie } & & \multicolumn{4}{|c|}{ Tempo de permanência $(\mathrm{P})$ e data da retirada dos coletores (D) } \\
\hline & Variável & $\begin{array}{c}P=7 \text { meses } \\
D=03 / 85\end{array}$ & $\begin{array}{c}P=8 \text { meses } \\
D=04 / 85\end{array}$ & $\begin{array}{c}\mathrm{P}=12 \text { meses } \\
\mathrm{D}=08 / 85\end{array}$ & $\begin{array}{c}\text { Total de } \\
\text { indivíduos em } \\
12 \text { meses } \\
\end{array}$ \\
\hline \multirow{3}{*}{$\begin{array}{l}\text { Nausitora } \\
\text { fusticula }\end{array}$} & Número total & 67 & 12 & 64 & 143 \\
\hline & Dominância \% & 85 & 92 & 84 & \\
\hline & Média/coletor & 3,3 & 1,2 & 12,8 & \\
\hline \multirow{3}{*}{$\begin{array}{c}\text { Bankia } \\
\text { fimbriatula }\end{array}$} & Número total & 11 & 0 & 2 & 13 \\
\hline & Dominância \% & 14 & 0 & 3 & \\
\hline & Média/coietor & 0,5 & 0 & 0,4 & \\
\hline \multirow{3}{*}{$\begin{array}{c}\text { Neoteredo } \\
\text { reynei }\end{array}$} & Número total & 0 & 0 & 10 & 10 \\
\hline & Dominância \% & 0 & 0 & 13 & \\
\hline & Média/coletor & 0 & 0 & 2 & \\
\hline \multirow[t]{3}{*}{ Bankia rochi } & Número total & 1 & 1 & 0 & 2 \\
\hline & Dominância \% & 1 & 8 & 0 & \\
\hline & Média/coletor & 0,05 & 0,1 & 0 & \\
\hline $\begin{array}{c}\text { Não } \\
\text { identificados }\end{array}$ & Número total & 27 & 0 & 0 & 27 \\
\hline
\end{tabular}


Das espécies encontradas, apenas Nausitora fusticula apresentou número suficiente de indivíduos para se construírem gráficos de frequiência de indivíduos por classes de comprimento (Fig. 3) e de curva de crescimento (Fig. 4). Foram medidos 98 indivíduos coletados completos e anestesiados.

A Figura 3-A mostra que no mês de março/85, após 7 meses da instalação dos coletores laminados da série de longa duração, houve incidência apenas de indivíduos das classes de comprimento entre $0,1 \mathrm{e}$ $5,0 \mathrm{~cm}$, com maior frequência na classe de 1,1 a 2,0 $\mathrm{cm}$. Esses dados sugerem infestação recente desses organismos, pois tratam-se de indivíduos pequenos para a espécie. Em abril/85 (Fig. 3-B), o número de indivíduos nos coletores foi muito reduzido, em relação aos outros meses. Entre abril e agosto/85 (Fig. 3-C), verificaram-se indivíduos de pequeno tamanho, porém em número reduzido, sugerindo também que a infestação de $N$. fusticula foi menor neste período que a constatada em março/85; o maior número de indivíduos concentrou-se nas classes de comprimento entre 7,1 e $13,0 \mathrm{~cm}$, sendo que o maior exemplar encontrado nesses coletores mediu 18,0 $\mathrm{cm}$.
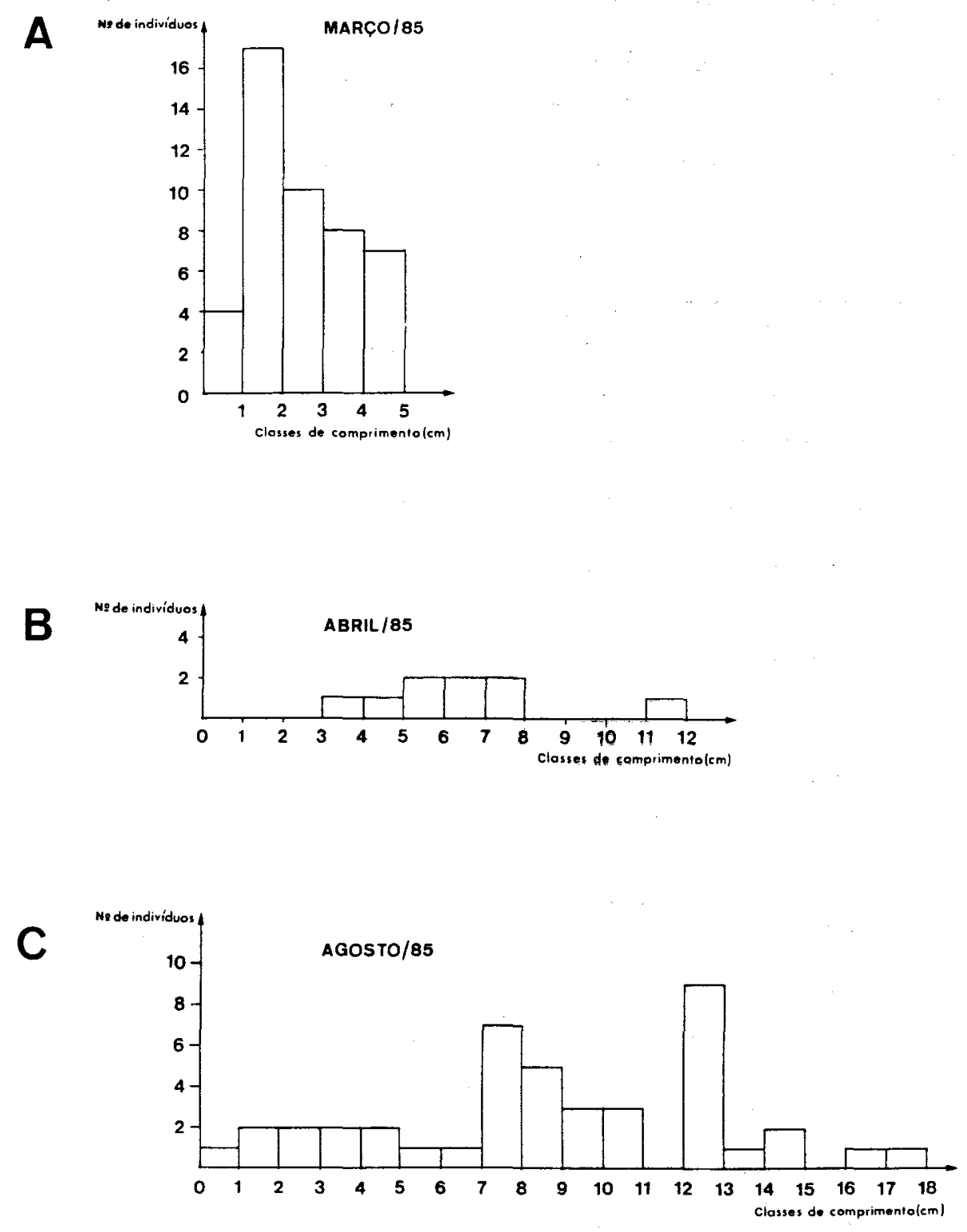

Fig. 3. Gráficos do número de indivíduos por classes de comprimento $(\mathrm{cm})$ de Nausitora fusticula, nos meses de (A) março, (B) abril e (C) agosto/85. 
A taxa de crescimento de $N$. fusticula no período de março a abril/85 foi de $1,86 \mathrm{~mm} / \mathrm{dia}$, reduzindo para $0,36 \mathrm{~mm} /$ dia no período de abril a agosto/85. Esses dados mostram um crescimento inicial rápido, diminuindo depois, como ocorre em geral no crescimento dos animais (Fig. 4).

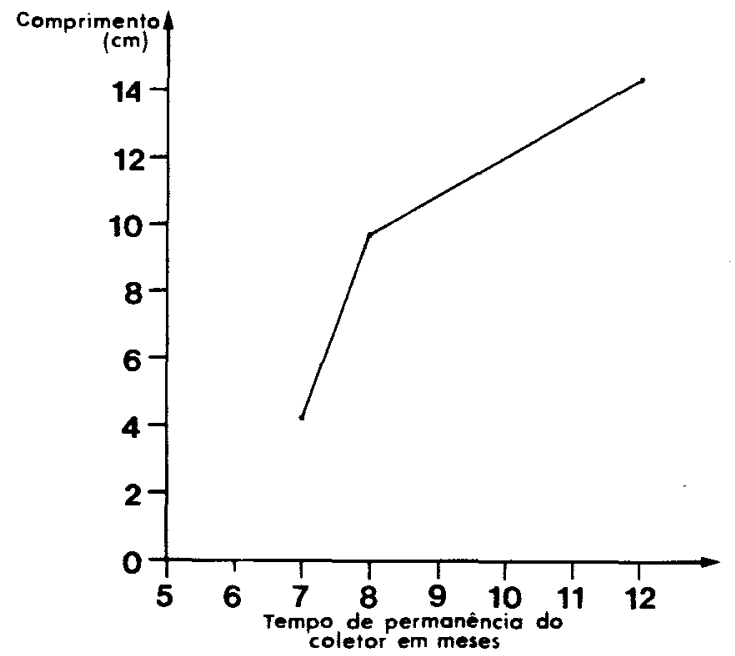

Fig. 4. Curva de crescimento de Nausitora fusticula.

Os dados de salinidade da água estão resumidos na Tabela 3. No interior do bosque próximo ao local do experimento (ponto E), a salinidade variou de 2 a 30. Esses valores nos dão uma idéia da salinidade da água que atinge essas regiões do bosque durante as preamares, mas não podem ser considerados valores exatos, pois essas poças estão sujeitas à dessecação.

Tabela 3. Valores de salinidade (S) da água acumulada em poças na maré baixa no interior do bosque (ponto E), e da água do Rio Comprido, obtidos na maré alta, no ponto 1 .

\begin{tabular}{ccc}
\hline Local & Data & $\mathrm{S}$ \\
\hline \multirow{3}{*}{$\mathrm{E}$} & $23 / 09 / 84$ & 30 \\
& $21 / 10 / 84$ & 2 \\
& $22 / 11 / 84$ & 15 \\
& $21 / 12 / 84$ & 20 \\
& $06 / 03 / 85$ & 2 \\
& $18 / 04 / 85$ & 12 \\
& & \\
1 & $26 / 09 / 84$ & 26 \\
& $04 / 10 / 84$ & 28 \\
& $11 / 10 / 84$ & 32 \\
& $18 / 10 / 84$ & 6 \\
& $24 / 10 / 84$ & 33 \\
& $30 / 10 / 84$ & 28 \\
& $06 / 12 / 84$ & 27 \\
& $12 / 12 / 84$ & 32 \\
& $19 / 12 / 84$ & 7 \\
\hline
\end{tabular}

A salinidade da água superficial do Rio Comprido durante a maré alta variou de 6 a 33 .

\section{Discussão}

A análise comparativa dos dados referentes à instalação de Teredinidae em coletores da série de curta e de longa duração, mostra que, na região entremarés da área estudada, o tempo de permanência de um coletor para que ocorra infestação, situa-se entre 4 e 7 meses. Nos coletores da série de curta duração, que permaneceram até 4 meses no local, não houve infestação, mesmo nos meses em que esta ocorria nos coletores da série de longa duração.

Supôs-se inicialmente que, devido ao fato de os coletores terem sido instalados em região entremarés, as constantes exposições ao ar durante as marés baixas, retardariam o assentamento, pois poucas larvas suportariam essa condição estressante. Entretanto, Milano \& Lopez (1977/78), obtiveram instalação de teredos após três meses da instalação de coletores feitos com diversos tipos de madeira de interesse comercial, mantidos submersos na região estuarino-lagunar de Cananéia. Silva (1985) obteve resultados semelhantes com coletores de pinho instalados na Baía de Guanabara (RJ), onde não houve infestação por teredos nos 6 meses em que os coletores permaneceram submersos no local. $O$ fato do coletor estar sujeito a imersões e emersões alternadas não parece ser o responsável pela demora na instalação das larvas, embora essa ainda não possa ser uma conclusão definitiva. Para testar essa hipótese, experimentos com coletores feitos com madeira de mangue e coletores de pinho, deveriam ser instalados ao mesmo tempo no interior do bosque de mangue e imersos no estuário, a fim de obter dados comparativos para as mesmas épocas do ano.

Essa demora não foi verificada em coletores submersos, instalados em regiões marinhas, onde os valores de salinidade são mais elevados e menos variáveis. Nesses casos, a presença de teredos já se constata no $1^{\circ}$ mês e geralmente após 4 a 6 meses, os coletores estão bastante danificados pela atividade perfuradora desses animais (Silva, 1985; Tiago, 1989).

Silva (op. cit.) atribuiu a ausência de teredos nos coletores instalados na região estuarina da Baía da Guanabara à poluição do local e à baixa salinidade, que oscilou entre 15 e 20. Na região da Praia Dura a poluição é comparativamente muito menor e a amplitude de variação da salinidade é bem maior. Sabe-se que o decréscimo da salinidade faz com que o número de teredinídeos diminua consideravelmente (Kristensen, 1969). Lopes \& Narchi (1993) também constataram no Rio Comprido, Praia Dura, Ubatuba/SP, redução no número de espécies e de indivíduos ao longo de um gradiente decrescente de salinidade. Porém, na área onde foram instalados os 
coletores, observou-se que a quantidade de teredos presentes nos troncos adjacentes foi muito grande.

Os teredinídeos são bivalves encontrados em ambiente marinho e estuarino, com uma única espécie, Psiloteredo healdi (Bartsch, 1931), cuja ocorrência está citada apenas para áreas de rios onde a salinidade é muito baixa, freqüentemente chegando a zero (Turner, 1966; Lopes \& Narchi, 1993.). Não existem registros na literatura sobre teredinídeos vivendo em ambiente exclusivamente de água doce. Assim, além de madeira, os teredinídeos necessitam de água do mar. Em regiões estuarinas associadas a manguezais, onde a variação de salinidade é grande e ocorre variação no nível da maré, os teredinídeos são abundantes, demonstrando que esses organismos suportam bem esse estresse ambiental (Clapp \& Kenk, 1963; Turner, 1966, 1971; Rancurel, 1971; Muller \& Lana, 1986, 1987; Reis, 1990; Lopes \& Narchi, op. cit.).

Em ambiente de manguezal a quantidade de madeira disponível para a infestação desses animais é muito grande e há muito ácido húmico na água, o que parece propiciar o assentamento larval. Culliney (1973) verificou que ao adicionar ácido húmico na água havia o assentamento de larvas de teredo no fundo de aquários, mesmo sem a presença da madeira. Assim, como o ambiente de manguezal é bastante propício ao desenvolvimento da comunidade de teredos, poder-se-ia supor que a instalação das larvas desses organismos nesse ambiente fosse pelo menos tão rápida quanto no ambiente tipicamente marinho, o que não foi confirmado no presente trabalho.

$O$ intervalo de tempo de 7 meses para iniciar a colonização de Teredinidae nesse ambiente pode ser considerado muito grande quando comparado com os resultados obtidos por Silva (1985) e Tiago (1989) $\mathrm{em}$ ambiente marinho no litoral brasileiro. $\mathrm{O}$ número médio de 3,0 indivíduos/coletor no primeiro mês em que ocorreu a infestação por teredos e de 15,2 ind/coletor no quinto mês após o início da colonização por esses animais, é considerado pequeno quando comparado aos valores obtidos por (Silva, 1985) e Tiago (1989). Esses autores utilizaram coletores mantidos submersos em ambiente marinho e com menor área disponível para a instalação de larvas de teredos do que a área disponível nos coletores empregados no presente trabalho. Silva (op. cit.) obteve número médio máximo de 185,8 animais por coletor após 2 meses de imersão em Portogallo (RJ) e 94,2 indivíduos/coletor, após 3 meses de imersão em Piraquara (RJ). O menor número de indivíduos por coletor obtido por Tiago (op. cit.) para o Canal de São Sebastião foi de 31 e o maior foi de 1.647, sempre após 3 meses de imersão.
Os dados do presente trabalho concordam com os de Junqueira \& Silva (1991), com coletores imersos por até 3 meses na Lagoa da Tijuca (RJ). Esses autores obtiveram o maior valor médio de 3,4 indivíduos/coletor no local onde a salinidade variou de 34,0 a 17,2 enquanto que na região onde a salinidade variou de 21,3 a 5,2 , obtiveram apenas a média de 0,08 exemplar/coletor.

Os dados do presente trabalho, os de Junqueira \& Silva (1991), a observação de Silva (1985) sobre a ausência de teredos após 6 meses em coletores imersos em região estuarina, sugerem que não apenas a salinidade mais baixa, como também a maior amplitude entre os valores máximo e mínimo da salinidade, parecem interferir no assentamento das larvas de teredos nos coletores.

Associado ao fator salinidade, deve haver também alguma participação de outros fatores relacionados com modificações na madeira dos coletores, que interferem no sucesso da fixação das larvas de teredos. A formação de um filme de bactérias na superficie do substrato é usualmente essencial para 0 desenvolvimento da comunidade marinha de "fouling" (Mitchell \& Küchman, 1984). Sendo o ambiente em estudo um estuário, poderíamos supor que esse filme de bactérias demore mais para se formar em função da salinidade ser menor e mais variável do que a verificada no ambiente tipicamente marinho. Entretanto, Camargo (1982) verificou que no complexo estuarino-lagunar de Cananéia (SP), a velocidade de estabelecimento de organismos incrustantes em substratos artificiais instalados na região entremarés foi maior nas margens do rio Taquari, onde a salinidade variou de 2 a 28 , que nas margens do rio Nóbrega, onde a salinidade variou de 6 a 30. Camargo (op. cit.) explica que esses resultados poderiam estar relacionados com a rápida deposição de uma camada fina de lodo, seguida do estabelecimento de uma comunidade primária constituída por bactérias, cianoficeas e diatomáceas nos substratos artificiais instalados na estação Taquari, onde a salinidade foi menor. Esses dados mostram que, apesar da salinidade na estação Nóbrega ser maior que na estação Taquari, a colonização do substrato na estação Nóbrega foi mais lenta. No ambiente onde foram instalados os coletores empregados para o presente trabalho, a salinidade variou de 2 a 33 . Comparando esses valores com os obtidos por Camargo (op. cit.) em Cananéia, verifica-se que a amplitude de variação no manguezal da Praia Dura foi maior, com o valor mínimo igual ao obtido na estação Taquari e o máximo, superior ao obtido na estação Nóbrega. Para o local em estudo, portanto, precisariam ser feitos mais experimentos para verificar a velocidade com que começa a haver a 
formação de um substrato primário e se ele é importante para a instalação de larvas de teredos. Os dados disponíveis não nos permitem fazer correlações entre o fator salinidade e a velocidade de formação de uma comunidade primária que pudesse interferir na instalação de teredinídeos no manguezal da Praia Dura.

Silva (1985) e Junqueira et al. (1989) referemse à presença de incrustação biológica como outro fator que interfere no assentamento das larvas de teredos nos coletores. Esses autores constataram a média de 0,2 indivíduos por coletor, após 8 meses de imersão dos mesmos em certos locais do litoral do Rio de Janeiro e atribuiram esse baixo valor à grande quantidade de organismos incrustantes que protegem a madeira, dificultando a penetração de larvas de Teredinidae. Isso não foi constatado no presente trabalho, pois a incrustação biológica foi praticamente ausente, não constituindo impecilho para a infestação. $O$ que se observou foi a presença de uma camada pouco espessa de sedimento recobrindo os coletores, que poderia ter interferido na infestação, justificando $o$ pequeno número de indivíduos encontrados. Entretanto, sobre os troncos adjacentes a esses coletores e abundantemente atacados por teredos, também se encontrou camada semelhante de sedimento. Essa camada talvez possa dificultar $o$ assentamento das larvas, mas uma vez a larva tendo assentado e iniciado a perfuração, ela não mais interfere no desenvolvimento do animal no interior da madeira. Lopes (1991) ao estudar a anatomia funcional de Nausitora fusticula, espécie de Teredinidae mais abundante no manguezal da Praia Dura, pode constatar que esses animais têm mecanismos bastante eficientes para viver em ambiente com muita partícula em suspensão na água e material depositado sobre os troncos. Nos troncos recobertos por sedimento e intensamente atacados por teredos no mesmo local do experimento, também pode ter ocorrido demora na instalação das larvas.

$O$ tipo de madeira poderia ser um fator responsável pela demora na instalação de larvas de teredos, mas a instalação de coletores de pinho no local e a baixa colonização desses coletores por teredos, sugere não ser a madeira de mangue a responsável pela demora na infestação. Poderíamos supor que as plantas de mangue teriam algum nível de resistência natural aos perfuradores de madeira, uma vez que elas convivem com esses organismos provavelmente desde o Eoceno. A evolução dos bivalves perfuradores de madeira deve ter ocorrido após o surgimento das plantas lenhosas, formas terrestres, cujos troncos e ramos poderiam ter sido introduzidos no ambiente marinho carreados pelas águas dos rios (Hoagland \& Turner, 1981). Posteriormente, com o surgimento de plantas lenhosas adaptadas à água salobra e salgada, os perfuradores de madeira teriam encontrado um ambiente propício e mais constante como fonte de substrato para a colonização e teriam se diversificado. Plaziat (1984) sugeriu inclusive, que os Teredinidae teriam evoluído concomitantemente com os ambientes de manguezais. Os registros fósseis trazem algum fundamento para essa hipótese, pois a época provável da diversificação dos teredinídeos é o. Eoceno (Turner, 1966), que é o mesmo período dos primeiros registros fósseis de plantas que compõem os manguezais (Chapman, 1984). Assim, restam ainda muitas questões a serem respondidas sobre a infestação por teredos em ambiente de manguezal.

A importância dos teredos na decomposição de macrodetritos vegetais em bosques de mangue foi registrada por Robertson (1991), quando afirma que a reciclagem da matéria orgânica contida em madeiras é mais rápida em manguezais do que em florestas terrestres onde não existem teredos. Em estuários, a decomposição da materia orgânica vegetal é de grande valor para as cadeias alimentares (Odum, 1971). Os estudos para se avaliar a decomposição de matéria orgânica vegetal em manguezal têm sido feitos a partir da degradação de folhas (Odum, 1971; Cintrón \& Schaeffer-Novelli, 1981). Nos objetivos iniciais do presente trabalho, pretendíamos fornecer também dados sobre o tempo que um tronco leva para ser degradado pela ação de teredos no manguezal da Praia Dura, deixando disponível para a cadeia alimentar detritívora, a matéria orgânica contida na madeira. A demora na instalação das larvas nos coletores, não permitiu que, no prazo de um ano, pudéssemos fornecer dados mais efetivos sobre esse tema, mas levantou uma série de questionamentos importantes para um planejamento de futuros experimentos nessa linha.

No presente trabalho verificou-se também que os coletores maciços demoraram mais tempo para serem infestados por teredos e, além disso, o número de indivíduos também foi menor que $o$ encontrado nos coletores laminados. Esses dados contrastam com os de Silva (1985) e Junqueira et al (1991) que, trabalhando com coletores laminados e sólidos submersos por até 7 meses no litoral do Rio de Janeiro, obtiveram maior densidade de perfuradores nos coletores sólidos.

A espécie mais abundante de Teredinidae encontrada nos coletores do presente trabalho foi Nausitora fusticula, que é a espécie mais comum no bosque de mangue da Praia Dura, conforme mostram os resultados de Lopes \& Narchi (1993). As demais espécies foram pouco frequientes. Em função disso, pôde-se construir gráfico da curva de crescimento somente dessa espécie. Esse gráfico mostra que há um crescimento inicial rápido, com taxa estimada de 
$1,86 \mathrm{~mm} /$ dia no primeiro mês e que esse crescimento diminui nos quatro meses seguintes, com taxa estimada de $0,36 \mathrm{~mm} /$ dia.

Comparando essas taxas de crescimento com as verificadas por Silva (1985) para Lyrodus pedicellatus e Teredo furcifera, verifica-se que $N$. fusticula apresenta um crescimento inicial um pouco mais rápido. As duas primeiras espécies apresentaram como maior taxa de crescimento o valor de $1,0 \mathrm{~mm} /$ dia. $N$. fusticula apresenta crescimento mais lento em relação à Bankia gouldi, cuja taxa inicial de crescimento estimada por Silva (op. cit.) foi de $2,6 \mathrm{~mm} / \mathrm{dia}$.

Quanto à época de instalação verificou-se que $N$. fusticula apresentou maior número de indivíduos de pequeno tamanho no mês de março/85. Esses dados coincidem com os obtibos em laboratório por Hiroki et al (1994) que observaram para Nausitora fusticula comportamento de pseudo-cópula e intensa eliminação de espermatozóides na água no mês de fevereiro. Com relação às demais espécies, o pequeno número de indivíduos não permitiu maiores conclusões.

\section{Conclusões}

O tempo para iniciar o recrutamento de Teredinidae em coletores instalados na região entremarés de manguezais é consideravelmente maior que o necessário para o recrutamento em coletores submersos, instalados em regiớes marinhas.

O tempo maior para $o$ recrutamento de Teredinidae em regiões estuarinas em relação ao ambiente marinho pode estar relacionado à maior variação da salinidade que ocorre em regiões estuarinas.

$\mathrm{O}$ número de indivíduos por coletor em ambiente entremarés do manguezal foi consideravelmente menor que o obtido por outros autores em coletores instalados em regiões marinhas.

A espécie de Teredinidae mais abundante nos coletores (Nausitora fusticula) é também a mais abundante no manguezal estudado. Sua principal época de recrutamento ocorre em março e sua taxa de crescimento está próxima das obtidas para outras espécies do grupo, por outros autores.

\section{Agradecimentos}

Agradecemos à FAPESP pela concessão de Bolsa de Auxílio à Pesquisa, processo número $84 / 1020-0$, e à Base Norte do Instituto Oceanográfico da USP pelas facilidades oferecidas para os trabalhos de campo. Especial agradecimento ao Sr. José de Oliveira que contribuiu efetivamente nos trabalhos de campo.

\section{Referências bibliográficas}

Camargo, T. M. 1982. Comunidades naturais de raízes de mangue-vermelho (Rhizophora mangle L.) e experimentos com substratos artificiais na região de Cananéia $\left(25^{\circ}\right.$ lat. S), Brasil. Dissertação de mestrado. Universidade de São Paulo, Instituto Oceanográfico. 102p.

Chapman, V. J. 1984. Mangrove biogeography. In: Por, F. D. \& Dor, I. eds Hydrobiology of the mangal. The Hague, Dr W. Junk. p. 15-24.

Cintrón, G. \& Schaeffer-Novelli, Y. 1981. Roteiro para estudo dos recursos de marismas $e$ manguezais. Relat. int. Inst. oceanogr. Univ. S Paulo, (10):1-13.

Clapp, W, F. \& Kenk, R. 1963. Marine borers: na annotated bibliography. Washington, Office of Naval Research Departament of the Navy. 1136p.

Culliney, J. L. 1973. Settling of larval shipworms Teredo novalis L. and Bankia gouldi Bartsch, stimulated by humic material (Gelbstoff). In: Acker, R. F. et al. eds Materials in the sea. Evanston, Northwestern, University Press. p. 822-829.

Hiroki, K.; Leonel, R. M. V. \& Lopes, S. G. B. C. 1994. Reproductive events of Nausitora fusticula ( Mollusca- Bivalvia- Teredinidae) . Invert. Reprod. Develop. , 26(3):247-250.

Hoagland, K. E. \& Turner, R. D. 1981. Evolution and adaptation radiation of wood- boring bivalves (Pholadacea). Malacologia, 21(1/2):111148.

Junqueira, A. de O. R. ; Silva, S. H. G. da \& Martins-Silva, M. J. 1989. Avaliação da infestação e diversidade de Teredinidae (Mollusca-Bivalvia) ao longo da costa do Estado do Rio de Janeiro, Brasil. Mems Inst. Oswaldo Cruz, 81:275-280. (Suplemento 4).

Junqueira, A. de O. R.; Omena, E. P. \& Silva, S. H. G. da 1991. A comparative study of the methods used to evaluate the activity of Teredinidae mollusks. J. expl mar. Biol. Ecol., (150):107115. 
Junqueira, A. de O. R. \& Siva, S. H. G. da 1991. Estudo experimental dos Teredinidae Rafinesque, 1815 (Mollusca-Bivalvia) do estuário da Lagoa da Tijuca, Rio de Janeiro, RJ, Brasil. Revta bras. Biol., 51(1):113-126.

Kristensen, I. 1969. Attacks by Teredo navalis on inner Danish waters in relation to environmental factors. Vidensk. Meddr dansk naturh. Foren., 132:199-210.

Lopes, S. G. B. C. 1991. Sobre a anatomia funcional de Nausitora fusticula (Jeffreys, 1860) (Mollusca-Bivalvia) e contribuição ao conhecimento dos Teredinidae da Praia Dura, Ubatuba (SP), Brasil. Tese de doutorado. Universidade de São Paulo, Instituto de Biociências. 169p.

Lopes, S. G. B. C. \& Narchi, W. 1993. Levantamento e distribuição das espécies de Teredinidae (Mollusca-Bivalvia) na manguezal da Praia Dura, Ubatuba, SP. Bolm Inst. oceanogr., S Paulo, 41(1/2):29-38.

Milano, S. \& Lopez, G. A. C. 1977/78. Resistência natural de madeiras a xilófagos marinhos: resultados da primeira avaliaçăo após três meses de instalação do ensaio. Preservação de Madeiras, 8/9(1):23-30.

Mitchell, R. \& Kirchman, D. 1984. The microbial ecology of marine Sur Gales. In: Costlow, J. D. \& Tipper, R. C. eds Marine biodeterioration: an interdisciplinary study. Annapolis, Naval Institute. p. 49-56.

Müller, A. C. \& Lana, P. C. 1986. Teredinidae (Mollusca-Bivalvia) do litoral do Paraná. Nerítica, Pontal do Sul, 1(3):27-48.

Müller, A. C. \& Lana, P. C. $1987 . \quad$ Padrões de distribuição geográfica de Teredinidae (BivalviaMollusca) do Estado do Paraná. Ciênc. Cult., S Paulo, 39:1175-1177.
Nair, N. B. 1962. Ecology of marine fouling and wood-boring organisms of Western Norway. Sarsia, 8:1-99.

Odum, E. P. 1971. Fundamentals of ecology. $3^{\text {rd }}$ ed. Philadelphia, Saunders. 574p.

Plaziat, C. F. A. 1984. Mollusk distribution in the mangal. In: Por, F. D.; Dor, I. eds Hydrobiology of the mangal. The Hague, Dr W. Junk. p. 111143.

Rancurel, P. 1971. Les Teredinidae (Mollusques lamellibranches) dans les lagunes de Côte d 'Ivoire. Mem. Off. rech. Scient tech. Outre-mer., 47:1-235.

Reis, R. E. M. L. 1990. Moluscos bivalves perfuradores de madeira do Estado do Pará, Brasil: caracterização taxonômica, distribuição e resistência de madeiras. Dissertação de mestrado. Universidade Federal do Pará, Centro de Ciências Biológicas - Museu Paraense Emílio Goeldi. 91p.

Robertson, A. I. 1991. Plant-anatomy interactions and the structure and function of mangrove forest ecosystems. Austr. J. Ecol. , 16:433-443.

Silva, S. H. G. 1985. Estudo experimental sobre a infestação de perfuradores marinhos de madeira da costa do Estado do Rio de Janeiro. Tese de doutorado. Universidade de São Paulo, Instituto de Biociências. 231p.

Tiago, C. G. 1989. Sobre uma comunidade de teredinídeos (Mollusca-Bivalvia) em São Sebastião (SP), Brasil. Dissertação de mestrado. Universidade de São Paulo, Instituto de Biociências. 88p.

Turner, R. D. 1966. A survey and illustrated catalogue of the Teredinidae (MolluscaBivalvia). Cambridge, The Museum of Comparative Zoology. 265p. 
Turner, R. D. 1971. Identification of marine-boring mollusks. In: Jones, E. B. \& Eltringham, S. K. eds Marine borers, fungi and fouling organisms of wood. Paris, Organisation for Economic Cooperation and Development. p.17-64.

(Manuscrito recebido 22 maio 1997; revisado 28 agosto 1997; aceito 12 dezembro 1997) 